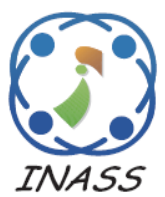

\title{
Sliding Mode Control Using SVM for Power Quality Enhancement in Stand- Alone System Based on Four-Leg Voltage
}

\author{
Ammar Djerioui $^{1^{*}} \quad$ Dehimi Ouali $^{1} \quad$ Mohamed Ladjal $^{2}$ \\ ${ }^{1}$ Department of Chemistry, University of M'sila,Ichbilia Street, M'sila 28000, Algeria \\ ${ }^{2}$ LASS, Laboratory of Analysis of Signals and Systems, PB No 166 Ichebilia, 28000 M'sila, Algeria \\ * Corresponding author's Email: alidjerioui@ yahoo.fr
}

\begin{abstract}
This paper proposes a sliding mode control strategy for hybrid power system (HPS). The hybrid power system consists of four-leg voltage source Inverter Bridge. The HPS ensures full compensation for harmonic phase currents, neutral current, reactive power compensation and unbalanced nonlinear load currents. The Sliding Mode control strategy with a three dimensional space vector modulation deals with power quality enhancement in standalone power-supply systems with the key objective to compensate for AC side load and phase disturbances that result essentially from the presence of nonlinear and unbalanced loads. The four-leg voltage source inverters play an important role by providing both balanced and unbalanced loads with clean power and balanced output voltage. The simulation results show that the performance of the four-leg HPS with the proposed control algorithm.
\end{abstract}

Keywords: Sliding mode control, Four-leg shunt active power filter, Space vector modulation, Stand-alone system.

\section{Introduction}

Micro-grids based on renewable energy a source that encompasses multiple generating units, storage elements, loads and power converter interfaces are seen as a promising architecture in the future generating plants [1]. Chosen for their high power density, high efficiency, low noise and environment friendly $[1,2]$, fuel cells is considered as a promising solution for embedded applications (city buses, submarines, tram, or locomotives) [3, 4]. Meanwhile, as the development of DG (Distributed Generation), combined heat and power system dominated by fuel cell [5]; complementary power generation system [6] consisting of fuel cell, wind energy and solar energy, and hybrid power system [7] consisting of fuel cell and gas turbine are derived.

Fuel cells are like a battery and consist of a container, an anode, a cathode, catalysts, an intervening electrolyte, and an attached electrical circuit. In that it converts the chemical energy from a fuel into electricity through a chemical reaction of positively charged hydrogen ions with oxygen or another oxidizing agent [5]. There are types of fuel cells which can vary from tiny devices producing only a miliwatts of electricity, right up to large power plants producing megawatts $[6,7]$. Fuel cells have a number of advantages over conventional power generating equipment: High efficiency, Low chemical, acoustic, thermal emissions, Siting flexibility, Reliability, Low maintenance, Modularity, and Fuel flexibility. Different energy management strategies for fuel-cell based hybrid power systems have been reported in the literature. These methods can be classified in four families, i.e rule based methods, controller methods, filter and optimization based methods. Concerning the rule based techniques, the principal ones are: state machine, fuzzy logic and Neural Networks. For state machine control $[8,9]$ each rule or state is defined based on heuristic or empiric past experience. Another rule strategy is based on fuzzy logic [10], where a membership functions are associated to the inputs and the outputs in order to achieve the desired performance. As statement, the performance of rule based strategies depends highly on the knowledge of the system. 


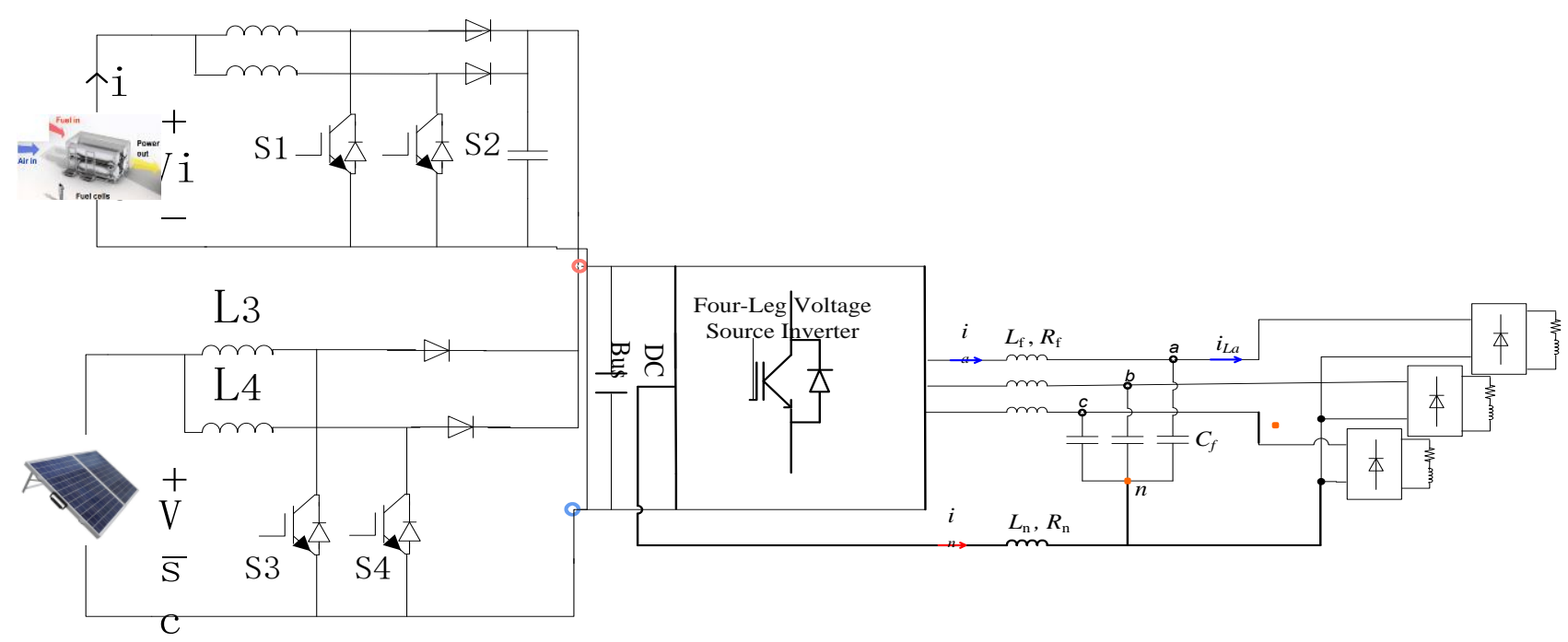

Figure. 1 Four-leg inverter topology with an output LC filter

In this context, the use of a four-leg voltage source inverter topology involves interest to maintain balanced sinusoidal output voltage waveform with required quality standards over all loading condition in transformerless applications [16]. With unbalanced load condition, to balance the microgrid, the additional leg provides a path for the resulting zero-sequence current. In addition, the use the added leg allows to increase the output voltage range and to reduce the dc-link capacitors, in comparison to the direct connection of the neutral point of the load to the midpoint of the dc-link [1719]. This power electronic structure is commonly equipped with an output low-pass filter such as an LC filter to reduce the inverter output current ripple and attenuate high frequency voltage components due to the switching harmonics.

In this work an efficient control scheme is proposed for power quality enhancement in a standalone system based on a four-leg voltage source inverter. This controller is based on the hybridization of a sliding mode controller with a SVM (SMC-SVM). In one hand, a cascaded sliding controller (SMC) delivers the main inverter input control and it is structured in an outer voltage and an inner current loops. Sliding-mode control techniques even they are suited for power industrial applications due to their robustness under critical working conditions (disturbances and perturbations), their use in four leg with LC filter with an output LC filter is on date rarely reported in the literature. In the found research works [13, 14], this technique seem to be well adapted for four leg inverter with an output LC filter. Several control approaches to minimize the Chattering in Induction-Motors, 6 DOF Octorotor, Doubly-Fed Induction Motor and
Wind Energy Conversion have been reported in the literature [7-14].

The main idea of the present manuscript is to combine the robustness capability of a sliding mode controller and the modulation task can be carried out with three dimensional space vector modulations, which operate under a constant switching frequency to enhance the power quality of UPS systems in critical operating constraints like the presence of heavy nonlinear and unbalanced loads. The proposed output voltage control strategy deals with power quality enhancement in standalone powersupply systems with the key objective to compensate for AC side load and phase disturbances that result essentially from the presence of nonlinear and unbalanced loads.

The paper is structured as follows. In Section II, the model of the studied system is presented, and, in Section III, the sliding mode controller with SVM is derived. Section IV presents simulation results and discusses the effectiveness of the proposed approach. Finally, provides a conclusion of the present work.

\section{System description and modelling}

The hybrid power system (HPS) is composed of a fuel cell and SCs as the main and auxiliary sources. Fig. 1 depicts a typical UPS system where a PV panels and Fuel cells are connected to the common $\mathrm{dc}$ bus via DC/DC converters. It delivers the primary power in the DC bus which will be converted into AC power via a four-leg inverter source inverter (VSI) with an output LC filter. This part creates a microgrid with constant amplitude sinusoidal voltage and constant frequency at the PCC. 
By applying Kirchhoff voltage and current laws to the nodes given in Fig. 1, the system behavior in $a b c$ frame can be defined by:

$$
\begin{aligned}
& \boldsymbol{v}_{\boldsymbol{i}}=\boldsymbol{v}_{\boldsymbol{f}}+R_{f} \boldsymbol{i}_{\boldsymbol{f}}+L_{f} \frac{d \boldsymbol{i}_{\boldsymbol{f}}}{d t}-\left(R_{n} \boldsymbol{i}_{\boldsymbol{n}}+L_{n} \frac{d \boldsymbol{i}_{\boldsymbol{n}}}{d t}\right) \\
& C_{f} \frac{d \boldsymbol{v}_{f}}{d t}=\boldsymbol{i}_{\boldsymbol{f}}-\boldsymbol{i}_{\boldsymbol{L}_{\boldsymbol{a} \boldsymbol{b} \boldsymbol{c}}}
\end{aligned}
$$

The inverter and load neutral connections are respectively denoted by "n" and "o". To simplify the modeling, the following voltage and current vectors are defined:

$\mathbf{v}_{\mathbf{i}}=\left[v_{u o}, v_{v o}, v_{w o}\right]^{\mathrm{T}}, \quad \mathbf{v}_{\mathbf{f}}=\left[v_{a n}, v_{b n}, v_{c n}\right]^{\mathrm{T}}, \quad \mathbf{i}_{\mathbf{f}}=$ $\left[i_{a}, i_{b}, i_{c}\right]^{\mathrm{T}}, \mathbf{i}_{\mathbf{L} \_a b c}=\left[i_{L a}, i_{L b}, i_{L c}\right]^{\mathrm{T}}, \mathbf{i}_{\mathbf{n}}=\left[i_{n}, i_{n}, i_{n}\right]^{\mathrm{T}}$.

The LC filter line current and output voltage equations are obtained after elementary calculation into a synchronous Park reference frame.

$$
\left\{\begin{array}{c}
\dot{x}=A x+B u+L d \\
y=C x=I_{6} x
\end{array}\right.
$$

where $\mathbf{x}=\left[i_{0}, i_{d}, i_{q}, v_{c 0}, v_{c d}, v_{c q}\right]^{T}$ is the state space vector in Park frame, $\mathbf{u}=\left[u_{0}, u_{d}, u_{q}\right]^{\mathrm{T}}$ is the input vector and $\mathbf{d}=\mathbf{i}_{\mathbf{L}}=\left[i_{L 0}, i_{L d}, i_{L q}\right]^{\mathrm{T}}$ presents the load distrbance. $\mathbf{C}=\mathbf{I}_{\mathbf{6}}$ is identity matrix and A, B,C are detailed in Appendix.

The following transformation are used: $\mathbf{u}=$ $\left[\mathrm{u}_{0}, \mathrm{u}_{\mathrm{d}}, \mathrm{u}_{\mathrm{q}}\right]^{\mathrm{T}}=\mathbf{P}(\boldsymbol{\theta}) \mathbf{v}_{\mathrm{i}}, \quad \mathbf{v}_{\mathbf{c}}=\left[\mathrm{v}_{\mathrm{c} 0}, \mathrm{v}_{\mathrm{cd}}, \mathrm{v}_{\mathrm{cq}}\right]^{\mathrm{T}}=$ $\mathbf{P}(\boldsymbol{\theta}) \mathbf{v}_{\mathbf{f}}, \quad \mathbf{i}=\left[\mathrm{i}_{0}, \mathrm{i}_{\mathrm{d}}, \mathrm{i}_{\mathrm{q}}\right]^{\mathrm{T}}=\mathbf{P}(\boldsymbol{\theta}) \mathbf{i}_{\mathbf{f}}, \mathbf{i}_{\mathbf{L}}=\left[\mathrm{i}_{\mathrm{L} 0}, \mathrm{i}_{\mathrm{Ld}}\right.$, $\left.\mathrm{i}_{\mathrm{Lq}}\right]^{\mathrm{T}}=\mathbf{P}(\boldsymbol{\theta}) \mathbf{i}_{\mathbf{L}_{-} \mathbf{a b c}}$.

\section{Fuel cell system model}

Most fuel cell power systems comprise a number of components, or building block, of a fuel cell consists of an electrolyte layer in contact with an anode (negatively charged electrode), and a cathode (positively charged electrode), on either side. At the anode the hydrogen gas is electrochemically dissociated into hydrogen ions $(\mathrm{H}+)$ and free electrons (e-). The electrolyte, an ionic conductive medium, acts as the separator between hydrogen and oxygen to prevent mixing and the resultant direct combustion. It completes the electrical circuit of transporting ions between the electrodes. The electrochemical reactions associated with hydrogen fuel are expressed in equations:

$$
\mathrm{H}_{2}+1 / 2 \mathrm{O}_{2} \rightarrow \mathrm{H}_{2} \mathrm{O}+2 e^{-}
$$

Anode reaction

$$
\mathrm{H}_{2} \rightarrow 2 \mathrm{H}^{+}+2 \mathrm{e}^{-}
$$

The combined effect of thermodynamics, mass transport kinetics and ohmic resistance determines the output voltage of the cell as [21]:

$$
V_{\text {cell }}=E_{\text {cell }}-\eta_{\text {act }}+\eta_{\text {ohmic }}+\eta_{\text {conc }}
$$

$\eta_{\text {ohmic }}$ Ohmic over voltage, $\eta_{\text {conc }}$ Concentration over voltage.Also the equilibrium electrode potential $\mathrm{E}$ is given by the Nernst equation [10]:

$$
E_{\text {cell }}=E_{0, \text { cell }}^{o}-k_{E}(T-298)+\begin{array}{r}
R T / 2 F \\
2 F \\
\left.\left.P_{O_{2}}^{*}\right)\right)
\end{array}
$$

Where $\mathrm{R}$ is gaz constant, $\mathrm{T}$ is absolute temperature, $\mathrm{F}$ is the Faraday constant, $\mathrm{E}_{0, \text { cell }}^{0}$ is the standard reference potential, $P^{*}$ The partial pressure in atm, , $\mathrm{k}_{\mathrm{E}}$ is the Empirical constant in calculating reference potential (in volts per Kelvin).

Activation over voltage nact which is dominant at low FC currents is caused by the slowness of the reactions taking place on the surface of the electrodes, which can be expressed as [10]:

$$
\eta_{\text {act }}=\xi_{1}+\xi_{2} T+\xi_{3} T \ln \left(\mathrm{co}_{2}\right)+\xi_{4} T \ln (I)
$$

where $\xi_{i(1-4)}$ are parametric coefficients for each cell model. $\mathrm{Co}_{2}$ is the concentration of dissolved oxygen at the gas/liquid interface $\left(\mathrm{mol} \mathrm{cm}{ }^{-3}\right)$.

Ohmic overvoltage ( $\left.\eta_{\text {ohmic }}\right)$ is due to the resistance to the flow electrons through the material of the electrodes and various interconnections. Ohmic overvoltage can be expressed as [4]:

$$
\eta_{\text {ohmic }}=-I R_{m}
$$

Concentration over voltage, this voltages drop results from the change in concentration of the reactants at the surface of the electrodes as the fuel is used and can be expressed as [2]:

$$
\eta_{\text {conc }}=-c \ln \left(1-\frac{I_{f c}}{I_{\text {lim }}}\right)
$$

A fuel cell stack consists of several cells in series to increase the voltage from fuel cell. In the following equation, Ncell is the number of cells in series. The output voltage of the fuel-cell stack can be obtained by:

$$
V=N_{\text {cell }} V_{\text {cell }}
$$

Dynamic of a fuel cell voltage can be modeled by an addition of a capacitor $\mathrm{C}$ to the steady state 
model. The capacitor represents the effect of double charge layer and is connected in parallel with activation resistance $[1,4]$.

\section{Sliding mode controller}

The output voltage loop provides the internal current loop references $\mathbf{i}^{\text {Ref }}=\left[i_{0}^{\text {Ref }}, i_{d}^{\text {Ref }}, i_{q}^{\text {Ref }}\right]^{\mathrm{T}}$. For this loop design, the associated state space model use the output capacitor filter equations and it is increased with their respective voltage errors in order to ensure a zero static error in steady state in presence of modeling errors or external perturbations. The voltage error vector is defined as:

$$
\zeta_{v}=\left[\begin{array}{l}
\zeta_{v 0} \\
\zeta_{v d} \\
\zeta_{v q}
\end{array}\right]=\left[\begin{array}{c}
v_{c 0} \\
v_{c d} \\
v_{c q}
\end{array}\right]-\left[\begin{array}{c}
v_{a c 0}^{R e f} \\
v_{a c d}^{R e f} \\
v_{a c q}^{R e f}
\end{array}\right]
$$

where $v_{c 0}, v_{c d}, v_{c q}$ are the output voltages and $v_{a c 0}^{R e f}, v_{a c d}^{R e f}, v_{a c q}^{R e f}$ are the references. The associated state space model to the outer voltage loop can be written as:

$$
\begin{aligned}
\dot{\boldsymbol{y}}_{v} & =\left[\begin{array}{cccccc}
0 & 0 & 0 & 0 & 0 & 0 \\
0 & 0 & \omega & 0 & 0 & 0 \\
0 & -\omega & 0 & 0 & 0 & 0 \\
1 & 0 & 0 & 0 & 0 & 0 \\
0 & 1 & 0 & 0 & 0 & 0 \\
0 & 0 & 1 & 0 & 0 & 0
\end{array}\right] \boldsymbol{y}_{v} \\
& +\left[\begin{array}{ccc}
\frac{1}{C_{f}} & 0 & 0 \\
0 & \frac{1}{C_{f}} & 0 \\
0 & 0 & \frac{1}{C_{f}} \\
0 & 0 & 0 \\
0 & 0 & 0 \\
0 & 0 & 0
\end{array}\right] \boldsymbol{u}_{v}+\left[\begin{array}{c}
\frac{-i_{L 0}}{C_{f}} \\
\frac{-i_{L d}}{C_{f}} \\
\frac{-i_{L q}}{C_{f}} \\
-v_{c 0}^{R e f} \\
-v_{c d}^{R e f} \\
-v_{c q}^{R e f}
\end{array}\right]
\end{aligned}
$$

where the state variable vector $\mathbf{y}_{\mathbf{v}}=\left[\boldsymbol{v}_{\mathbf{c}}, \boldsymbol{\zeta}_{\mathbf{v}}\right]^{\mathrm{T}}$ regroup the output voltages and their respective errors.

The input vector $\mathbf{u}_{\mathbf{v}}=\left[i_{0}, i_{d}, i_{q}\right]^{\mathrm{T}}$ presents the line currents. The matrices $\mathbf{A}_{\mathbf{v}}$ and $\mathbf{B}_{\mathbf{v}}$ and the disturbance vector $\mathbf{C}_{\mathbf{v}}$ are detailed in Appendix. To track the suited reference voltage trajectories, an exponent reaching law with respect to the error in output capacitor filter voltages is proposed. The vector form of the 0dq-axis sliding surface noted $\mathbf{s}_{\mathbf{v}}=\left[s_{v 0}, s_{v d}, s_{v q}\right]^{\mathrm{T}}$ is defined as:

$$
\boldsymbol{s}_{v}=\dot{\zeta}_{v}+K_{v} \zeta_{v}
$$

where $\mathbf{K}_{\mathbf{v}}=k_{v} \mathbf{I}_{\mathbf{3}}$ with $k_{v}$ is constant whose the setting condition is provided in the stability paragraph. $\mathbf{I}_{3}$ is an identity matrix. The generated control input by the outer voltage loop should ensures that the output voltages at locations near the sliding surface $\mathbf{S}_{\mathbf{v}}$ will always be directed toward the sliding surface. This is satisfied when the first order derivative surface converge to zero $\left(\dot{\mathbf{s}}_{\mathbf{v}_{\mathrm{t} \rightarrow \infty}}=0\right)$. In this aim, we use the following reaching law:

$$
\begin{aligned}
\dot{s}_{v}=-\lambda_{v} s_{v} & -L_{v b} \operatorname{sgn}\left(s_{v}\right) \\
& =G_{v}\left(\dot{y}_{v}-\dot{y}_{v}^{R e f}\right)
\end{aligned}
$$

where matrix $\mathbf{G}_{\mathbf{v}}$ is set as $\mathbf{G}_{\mathbf{v}}=\left[\mathbf{I}_{3}, \mathbf{K}_{\mathbf{v}}\right]$ and matrices $\boldsymbol{\lambda}_{\mathbf{v}}$ and $\mathbf{L}_{\mathbf{v}}$ are calculated respectively by $\boldsymbol{\lambda}_{\mathbf{v}}=l_{v} \boldsymbol{I}_{\mathbf{3}}$ and $\mathbf{L}_{\mathbf{v}}=q_{v} \boldsymbol{I}_{\mathbf{3}} \cdot l_{v}$ and $q_{v}$ are constants whose the setting is provided in the stability paragraph. Then, the outer voltage loop generates the input control $\mathbf{u}_{\mathbf{v}}$ which presents the reference input of the inner loop $\mathbf{i}^{\text {Ref }}$. This reference current $\mathbf{i}^{\text {Ref }}=\left[i_{0}^{R e f}, i_{d}^{R e f}, i_{q}^{R e f}\right]^{\mathrm{T}}$ can be defined by replacing Eq. (5) in Eq. (7).

$$
\begin{gathered}
i^{R e f}=\left[G_{v} B_{v}\right]^{-1}\left[-\lambda_{v} s_{v}-L_{v} \operatorname{sgn}\left(s_{v}\right)-\right. \\
\left.G_{v} A_{v} Y_{v}-G_{v} C_{v}+G_{v} \dot{Y}_{v}^{R e f}\right]
\end{gathered}
$$

The inner current loop generates the input controlu $\mathbf{u}^{\text {Ref }}=\left[u_{0}^{\text {Ref }}, u_{d}^{\text {Ref }}, u_{q}^{\text {Ref }}\right]^{\mathrm{T}}$.

For the inner current loop design, the line inductor filter dynamic equations can be increased by the dynamic equations of the 0dq-axis current errors, where this vector can be defined as:

$$
\zeta_{i}=\left[\zeta_{i 0}, \zeta_{i d}, \zeta_{i q}\right]^{T}=\boldsymbol{i}-\boldsymbol{i}^{\operatorname{Ref}}
$$

where $\mathbf{i}=\left[i_{0}, i_{d}, i_{q}\right]^{\mathrm{T}}$ is the line filter current vector and $\mathbf{i}^{\text {Ref }}=\left[i_{0}^{R e f}, i_{d}^{R e f}, i_{q}^{R e f}\right]^{\mathrm{T}}$ is its reference. Then, the increased model can be written as follows: 


$$
\begin{gathered}
\dot{\boldsymbol{y}}_{\boldsymbol{i}}=\left[\begin{array}{cccccc}
-\frac{R_{f}+3 R_{n}}{L_{f}+3 L_{n}} & 0 & 0 & 0 & 0 & 0 \\
0 & \frac{-R_{f}}{L_{f}} & \omega & 0 & 0 & 0 \\
0 & -\omega & \frac{-R_{f}}{L_{f}} & 0 & 0 & 0 \\
1 & 0 & 0 & 0 & 0 & 0 \\
0 & 1 & 0 & 0 & 0 & 0 \\
0 & 0 & 1 & 0 & 0 \\
0 & & & \\
1 & 0 & 0 \\
\frac{-v_{c 0}}{L_{f}+3 L_{n}} \\
\frac{-v_{c d}}{L_{f}} \\
\frac{-v_{c q}}{L_{f}} \\
-i_{0}^{R e f} \\
-i_{d}^{R e f} \\
-i_{q}^{R e f}
\end{array}\right] \\
+\left[\begin{array}{ccc}
\frac{1}{L_{f}+3 L_{n}} & 0 \\
0 & 0 & \frac{1}{L_{f}} \\
0 & 0 & 0 \\
0 & 0 & 0 \\
0 & 0 & 0
\end{array}\right] \boldsymbol{u}_{\boldsymbol{i}}
\end{gathered}
$$

where the state variable vector $\mathbf{y}_{\mathbf{i}}=\left[\mathbf{i},, \boldsymbol{\varepsilon}_{\mathbf{i}}\right]^{\mathrm{T}}$ regroup the line currents and their respective errors.

The input vector $\mathbf{u}_{\mathbf{i}}=\mathbf{u}=\left[u_{0}, u_{d}, u_{q}\right]^{\mathrm{T}}$ presents the input control of the four leg inverter. To track the suited reference current reference vector $\mathbf{i}^{\text {Ref }}=$ $\left[i_{0}^{R e f}, i_{d}^{R e f}, i_{q}^{R e f}\right]^{\mathrm{T}}$, the proposed sliding surface vector $\mathbf{s}_{\mathbf{i}}$ is:

$$
\begin{aligned}
& \boldsymbol{s}_{\boldsymbol{i}}=\dot{\boldsymbol{\zeta}}_{\boldsymbol{i}}+\boldsymbol{K}_{\boldsymbol{i}} \boldsymbol{\zeta}_{\boldsymbol{i}} \\
& \text { with: }\left\{\begin{array}{c}
\mathbf{s}_{\mathbf{i}}=\left[s_{i 0}, s_{i d}, s_{i q}\right]^{\mathrm{T}} \\
\mathbf{K}_{\mathbf{i}}=k_{i} \boldsymbol{I}_{\mathbf{3}}
\end{array}\right.
\end{aligned}
$$

By setting the derivative surface as

$$
\dot{\mathbf{s}}_{\mathbf{i}}=-\lambda_{\mathbf{i}} \mathbf{s}_{\mathbf{i}}-\mathbf{L}_{\mathbf{i}} \operatorname{sgn}\left(\mathbf{s}_{\mathbf{i}}\right)=\mathbf{G}_{\mathbf{i}}\left(\dot{\mathbf{y}}_{\mathbf{i}}-\dot{\mathbf{y}}_{\mathbf{i}}^{\text {Ref }}\right)
$$

where matrix $\mathbf{G}_{\mathbf{i}}$ is set as $\mathbf{G}_{\mathbf{i}}=\left[\mathbf{I}_{3}, \mathbf{K}_{\mathbf{i}}\right]$ and matrices $\lambda_{\mathbf{i}}$ and $\mathbf{L}_{\mathbf{i}}$ are calculated respectively by $\boldsymbol{\lambda}_{\mathbf{i}}=l_{i} \boldsymbol{I}_{\mathbf{3}}$ and $\mathbf{L}_{\boldsymbol{i}}=q_{i} \boldsymbol{I}_{\mathbf{3}} \cdot l_{i}$ and $q_{i}$ are constants whose the setting is provided in the stability paragraph.

Finally, the control input $\mathbf{u}^{\text {Ref }}=$ $\left[u_{0}^{R e f}, u_{d}^{R e f}, u_{q}^{R e f}\right]^{\mathrm{T}}$ of the four-leg voltage source inverter can be calculated by replacing (18) in (19).

$$
\begin{gathered}
\mathbf{u}^{\text {Ref }}=\left[\mathbf{G}_{\mathbf{i}} \mathbf{B}_{\mathbf{i}}\right]^{-\mathbf{1}}\left[-\boldsymbol{\lambda}_{\mathbf{i}} \mathbf{s}_{\mathbf{i}}-\mathbf{L}_{\mathbf{i}} \operatorname{sign}\left(\mathbf{s}_{\mathbf{i}}\right)-\mathbf{G}_{\mathbf{i}} \mathbf{A}_{\mathbf{i}} \mathbf{y}_{\mathbf{i}}-\right. \\
\left.\mathbf{G}_{\mathbf{i}} \mathbf{C}_{\mathbf{i}}+\mathbf{G}_{\mathbf{i}} \dot{\mathbf{y}}_{\mathbf{i}}^{\text {Ref }}\right]
\end{gathered}
$$

\subsection{Sliding mode stability}

The stability issue of the sliding controller is addressed by using the Lyapunov stability theory. Consider the Lyapunov function candidate is:
Table 1. Specifications of the studied system

\begin{tabular}{|c|c|c|}
\hline \multirow{3}{*}{ Inverter } & DC bus voltage & $400 \mathrm{~V}$ \\
\cline { 2 - 3 } & Switching frequency & $20 \mathrm{kHz}$ \\
\cline { 2 - 3 } & Sampling frequency & $20 \mathrm{kHz}$ \\
\hline \multirow{3}{*}{ Filtre } & Capacitor $\left(\mathrm{C}_{\mathrm{f}}\right)$ & $40 \mu \mathrm{F}$ \\
\cline { 2 - 3 } & Inductor $\left(\mathrm{L}_{\mathrm{f}}\right)$ & $2 \mathrm{mH}$ \\
\cline { 2 - 3 } & Inductor $\left(\mathrm{L}_{\mathrm{n}}\right)$ & $0.2 \mathrm{mH}$ \\
\hline
\end{tabular}

$$
\mathbf{V}=\frac{1}{2} \mathbf{s}^{2}
$$

where $\mathbf{s}=\left[\mathbf{s}_{\mathbf{v}}, \mathbf{s}_{\mathbf{i}}\right]^{\mathrm{T}}$.

To ensure that the state trajectory is maintained within the vicinity of the sliding line which ensures the sliding mode stability, the first derivative of the Lyapunov function must be negative.

$$
\begin{aligned}
\dot{\boldsymbol{V}} & =\dot{\boldsymbol{s}} \boldsymbol{s}<\mathbf{0} \\
\dot{\boldsymbol{V}} & =[-\lambda \boldsymbol{s}-\boldsymbol{L} \operatorname{sgn}(\boldsymbol{s})] \boldsymbol{s} \\
& =-\boldsymbol{L} \operatorname{sgn}(\boldsymbol{s}) \boldsymbol{s}<0
\end{aligned}
$$

where $\boldsymbol{\lambda}=\left[\boldsymbol{\lambda}_{\mathbf{v}}, \boldsymbol{\lambda}_{\mathbf{i}}\right]^{\mathrm{T}}$ and $\mathbf{K}=\left[\mathbf{K}_{\mathbf{v}}, \mathbf{K}_{\mathbf{i}}\right]^{\mathrm{T}}$.

Terms $\mathbf{s}^{\mathbf{2}}$ and $(\mathbf{s} \operatorname{sgn}(\mathbf{s}))$ are always a positive quantities, then the sliding mode stability condition is ensured if matrices $\boldsymbol{\lambda}$ and $\mathbf{K}$ are chosen strictly positives. This means that constants $l_{i}, l_{v}, q_{i}$ and $q_{v}$ must be chosen positive.

\subsection{SVM for the four-leg inverter}

In SVM, there are 16 possible switching vectors: fourteen active nonzero vectors and two null vectors. The entire 3-D Space is divided in 6 prisms and 24 tetrahedrons. Each prism consists of four tetrahedrons. An instantaneous reference input vector may lie in any of these tetrahedrons at any point of time [10]. The 3D-SVM algorithm is composed by four essential steps (Identification of prism; Identification of tetrahedrons; Duty cycle calculation; Generation of PWM sequence for the switches).

\section{Simulation results}

The SimPower Systems and S-Function of MATLAB are used for implemented the three phase four wire four leg controlled by nonlinear sliding mode technique Fig. 1. The parameters used are shown in Table 1.

To demonstrate the flexibility of the developed control strategy, it is applied to the case of fuel cells and $\mathrm{Pv}$ operating in parallel to supply the load. Although different approaches can be taken to determine how the demand should be shared between the two sources, here it is based solely on 
the relative capacity of each fuel cell, and the requested source currents are adjusted accordingly based on this relationship. The hybrid system is shown in Figure 1, and Figure 2 and Figure 3 below shows V-I characteristic of FC and PV For this, four operating conditions are considered.

Case (1): balanced resistive loads $\left(\mathrm{R}_{\mathrm{a}}=\mathrm{R}_{\mathrm{b}}=\right.$ $\left.\mathrm{R}_{\mathrm{c}}=15\right)$

The output waveforms of load voltages, load currents, harmonic spectrums of ac supply current and output voltage are reported in Figs 4 and 5. In the balanced load scenario, the neutral current is equal to zero and unity power factor operation is successfully achieved, even in this transient state. Their corresponding THD are respectively $1.12 \%$ and $1.14 \%$.

Case (2): unbalanced nonlinear loads as shown in Fig.6.

The Fig. 6 and 7 show the behavior of the current, voltage in Phase 1 of the HPS. It is noted the currents are non-sinusoidal and the control technique presents a very good dynamic behavior, almost sinusoidal as well as in phase with line voltage. Their corresponding THD are respectively 4.52 and $145.52 \%$. To summarize, this test indicates that the proposed control scheme compensator achieves lower THD values and enhances the output voltage symmetry. The proposed Sliding mode Control in HPS checks again the IEEE standard.
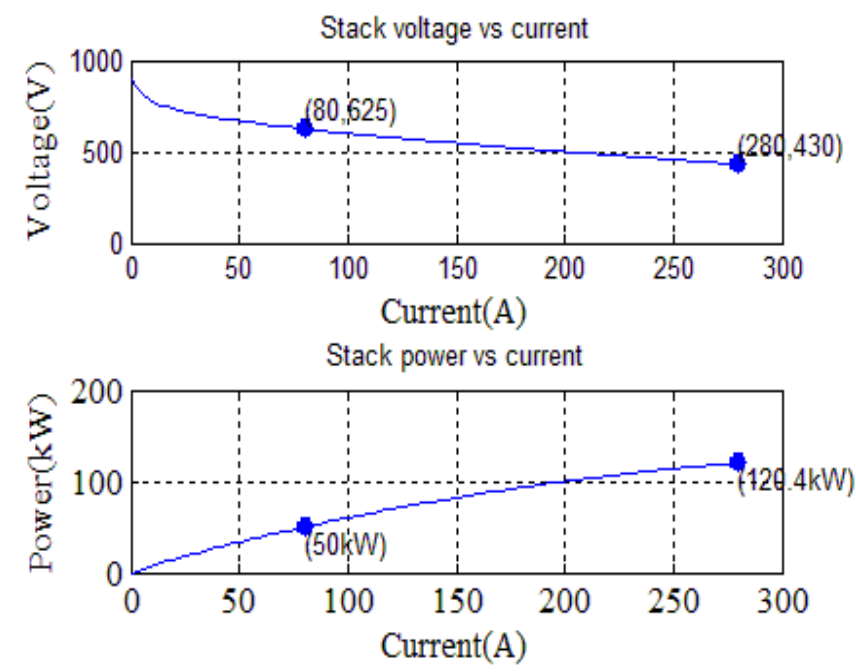

Figure. 2 V-I characteristic of fuel cell

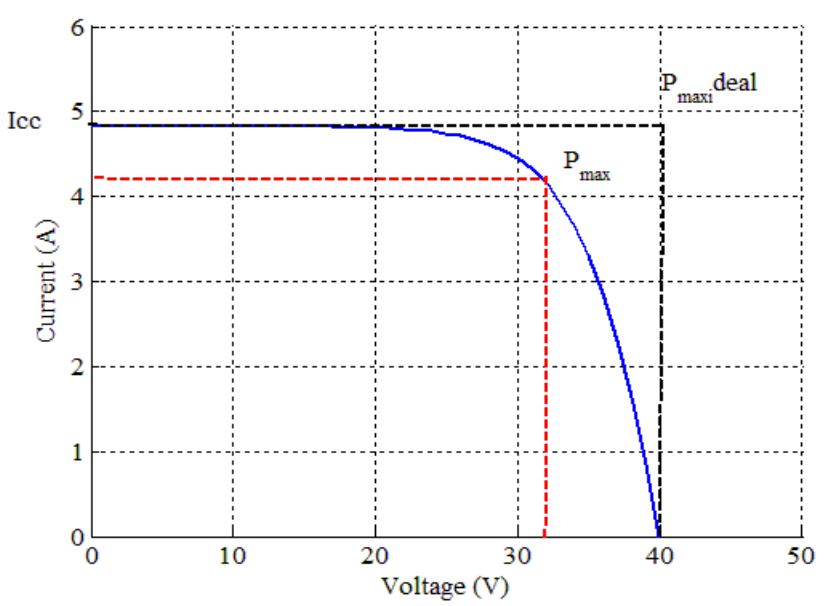

Figure. 3 V-I characteristic of PV
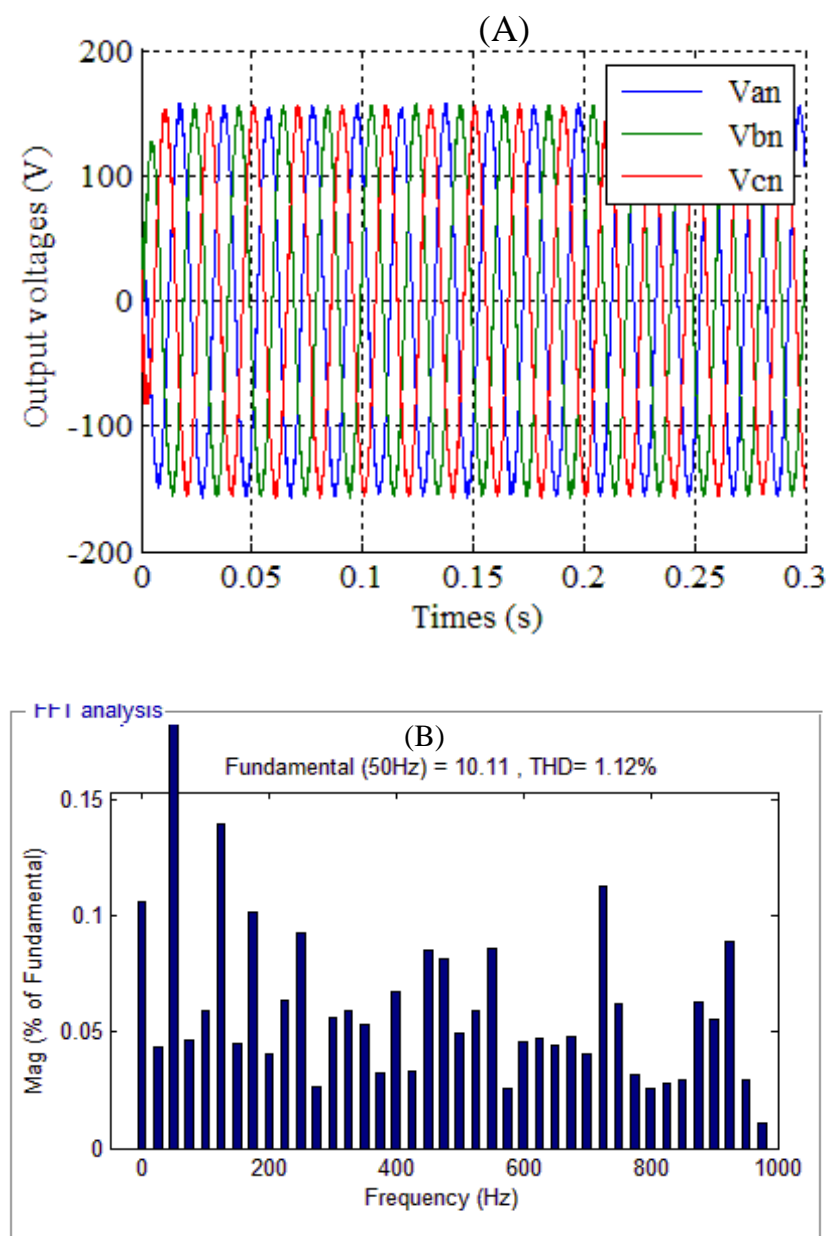

Figure. 4 Output voltage and spectrum harmonic waveforms for balanced resistive loads 

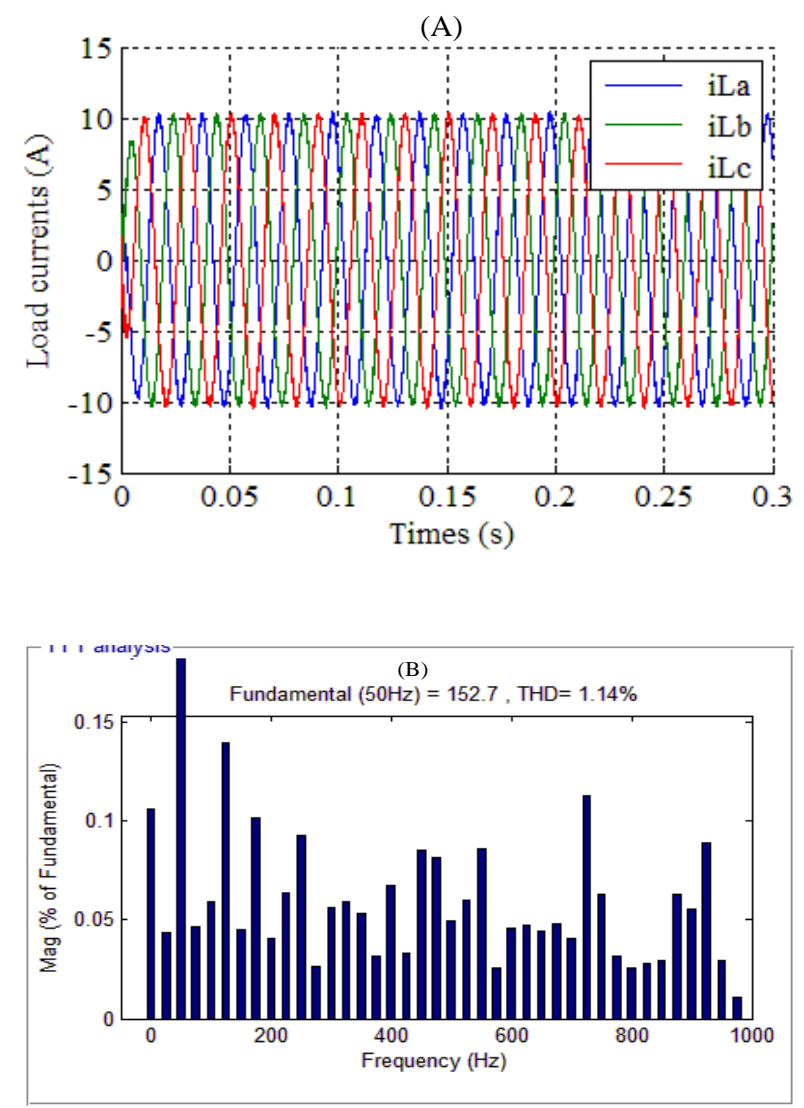

Figure. 5 Load current and spectrum harmonic waveforms for balanced resistive loads
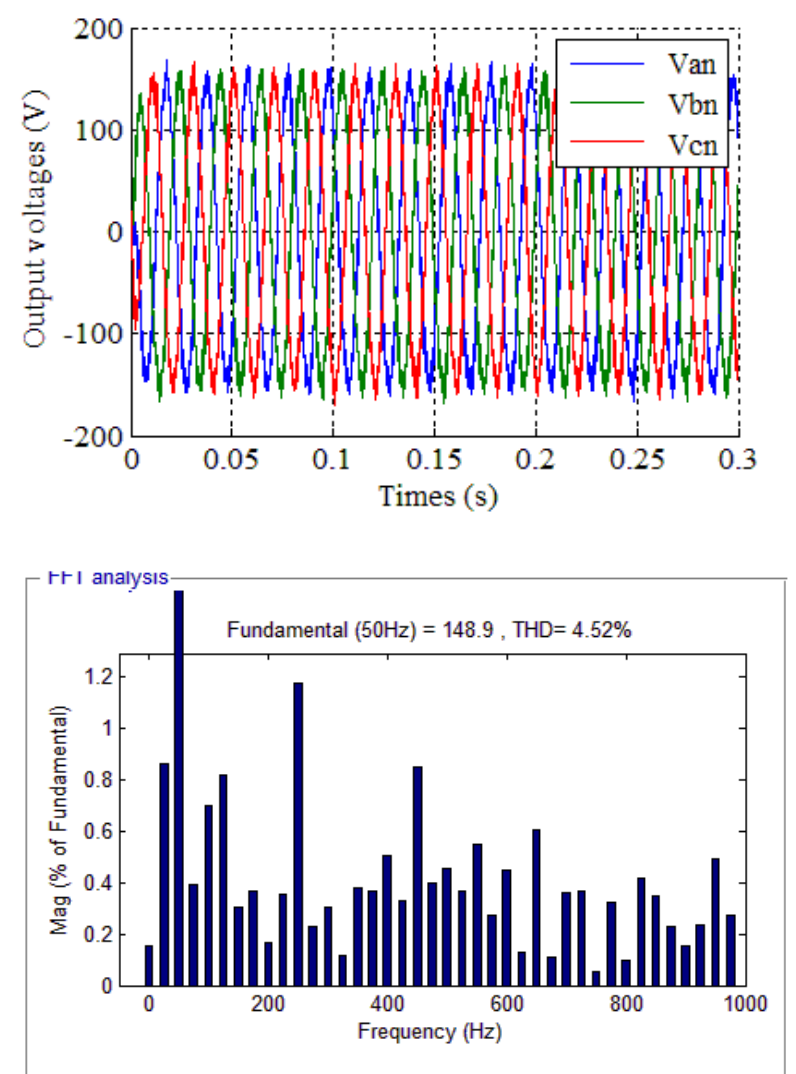

Figure. 6 Output voltage and spectrum waveforms for unbalanced nonlinear load

\subsection{Comparison between PI and sliding mode}

$\mathrm{T}$ To highlight the improvement of the proposed technique, a comparison with PI method. The design method for the PI controller is described in [18]. From this result, the analysis of the reported THD values regarding robustness against parameter variations proves that the proposed control allows obtaining a lower voltage THD value.
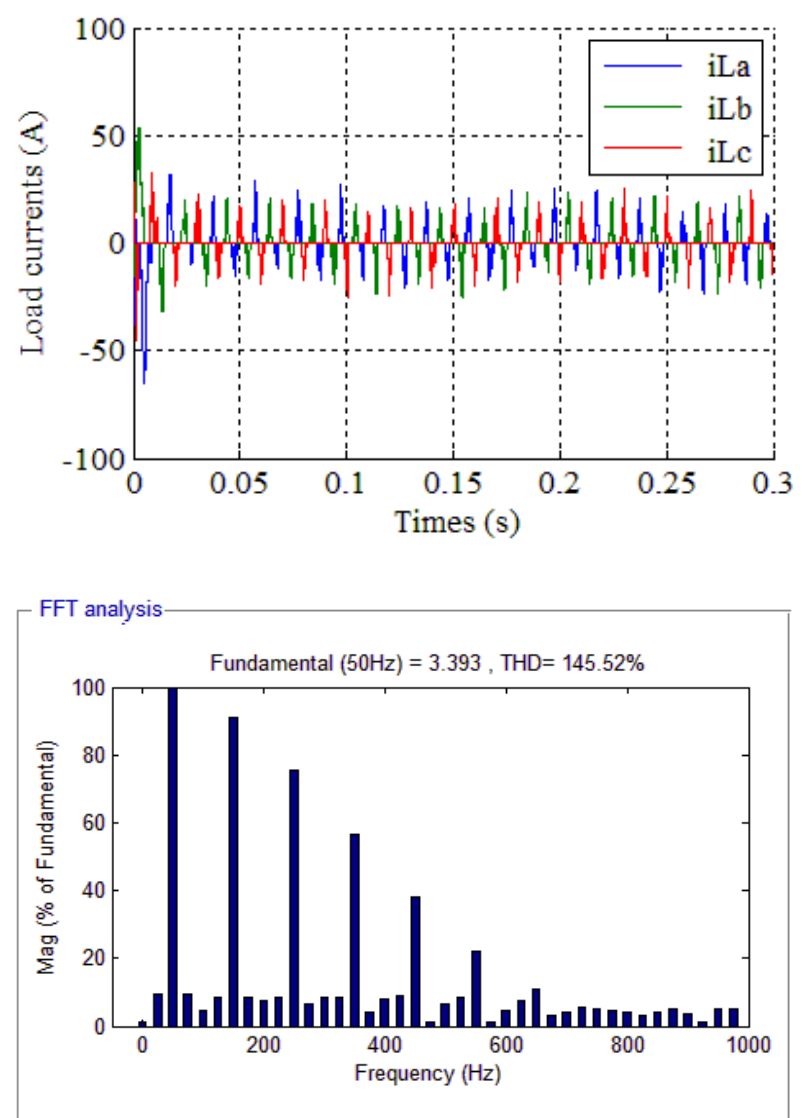

Figure. 7 Load current and spectrum waveforms for unbalanced nonlinear load

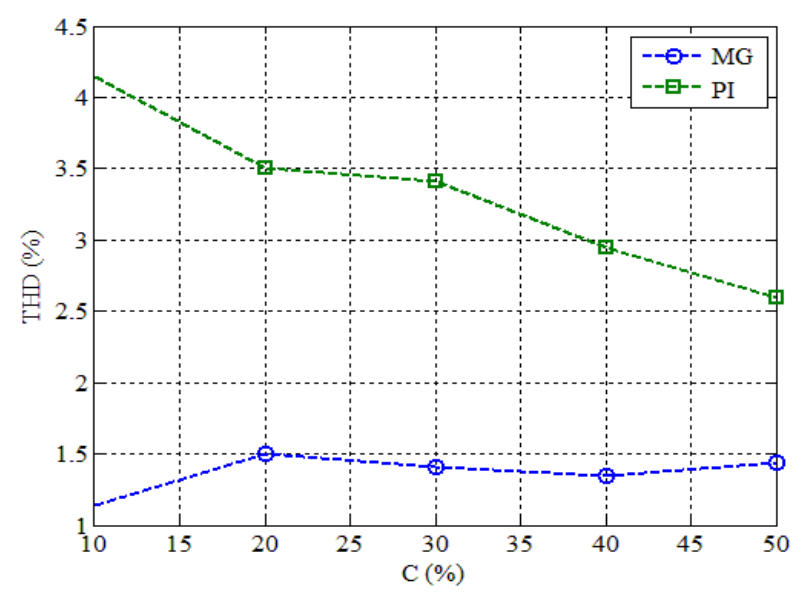

Fig.8. Waveforms for variation of THD versus the capacitance 


\section{Conclusion}

This work presented a sliding mode control technique applied to a three-phase four-leg (hybrid power system). The developed controller was aimed to compensate for harmonics and unbalance in the case of distorted nonlinear load currents, by making the source currents in phase with their corresponding phase voltages. Also, the controller was capable of eliminating the current flowing in the neutral line. The provided simulation demonstrated that the proposed approach allows enhancing the power quality when the system is subject to disturbances like the presence of heavy nonlinear loads and unbalanced loads. The simulation results verify the validity of the proposed control scheme. Unity power factor is achieved, active and reactive current are decoupled controlled in the synchronous reference. As perspective, further comparisons with advanced control methods like intelligence-based algorithms (PSO, ANN....) are needed to provide better comprehension on the sliding mode controller effectiveness under real time working conditions.

\section{Appendix}

The matrices $\mathbf{A}$ and $\mathbf{B}$ and the disturbance vector $\mathbf{C}$ :

$$
\begin{gathered}
\boldsymbol{A}=\left[\begin{array}{cccccc}
-\frac{R_{f}+3 R_{n}}{L_{f}+3 L_{n}} & 0 & 0 & \frac{-1}{L_{f}+3 L_{n}} & 0 & 0 \\
0 & \frac{-R_{f}}{L_{f}} & \omega & 0 & \frac{-1}{L_{f}} & 0 \\
0 & -\omega & \frac{-R_{f}}{L_{f}} & 0 & 0 & \frac{-1}{L_{f}} \\
\frac{1}{C_{f}} & 0 & 0 & 0 & 0 & 0 \\
0 & \frac{1}{C_{f}} & 0 & 0 & 0 & \omega \\
0 & 0 & \frac{1}{C_{f}} & 0 & -\omega & 0
\end{array}\right], \\
\boldsymbol{B}=\left[\begin{array}{ccc}
\frac{1}{L_{f}+3 L_{n}} & 0 & 0 \\
0 & \frac{1}{L_{f}} & 0 \\
0 & 0 & \frac{1}{L_{f}} \\
0 & 0 & 0 \\
0 & 0 & 0 \\
0 & 0 & 0
\end{array}\right], \boldsymbol{L}=\left[\begin{array}{ccc}
0 & 0 & 0 \\
0 & 0 & 0 \\
0 & 0 & 0 \\
\frac{-1}{C_{f}} & 0 & 0 \\
0 & \frac{-1}{C_{f}} & 0 \\
0 & 0 & \frac{-1}{C_{f}}
\end{array}\right]
\end{gathered}
$$

\section{References}

[1] C. C. Chan, A. Bouscayrol, and K. Chen, "Electric, hybrid and fuel cell vehicles: architectures and modelling," IEEE Transactions on Vehicular Technology, Vol. 59, No. 2, pp. 589-598, 2010.

[2] D. Hernandez-Torres, D. Riu, and O. Sename, "Design and Experimental Validation of a Robust Control Method for a Hybrid Fuel Cell
Power Generation System", IEEE Energy Conversion Congress \& Expo ECCE, 2010.

[3] D.D. Boettner, G. Paganelli, Y.G. Guezennec, G. Rizzoni, and M.J. Moran, "Proton Exchange Membrane Fuel Cell System Model for Automotive Vehicle Simulation and Control", Journal of Energy Resources and Technology, Vol. 124, No. 21, pp. 20 - 27, 2002.

[4] J. H. Scott, "The Development of Fuel Cell Technology for Electric Power Generation: From NASA's Manned Space Program to The Hydrogen Economy", In: Proc. of the IEEE, Vol. 94, No. 10, pp. 1815-1825, 2006.

[5] L. Wang, C. Shao, H. Wang, and H. Wu , 'Radial Basis Function Neural NetworksBased Modeling of the Membrane Separation Process: Hydrogen Recovery from Refinery Gases", Journal of Natural Gas Chemistry, Vol. 15, pp. 230-234, 2006.

[6] C. Wang, M.H. Nehrir, and S.R. Shaw, "Dynamic Models and Model Validation for PEM Fuel Cells Using Electrical Circuits", In: Proc. of the 2005 IEEE Power Engineering Society General Meeting, Vol. 3, p. 2115, 2005.

[7] A. Saengrung, A. Abtahi, and A. Zilouchian, "Neural network model for a commercial PEM fuel cell system", Journal of Power Sources, Vol. 172, No. 2, pp. 749-759, 2007.

[8] J. Arriagada, P. Olausson, A. Selimovic, "Artificial neural network simulator for SOFC performance prediction", Journal of Power Sources, Vol. 112, No. 1, pp. 54-60, 2002.

[9] X.J. Wu, X.J. Zhu, G.Y. Cao, and H.Y. Tu, "Predictive control of SOFC based on a GARBF neural network model", Journal of Power Sources, Vol. 179, No. 1, pp. 232-239, 2008.

[10] H. Hemi, J. Ghouili, and A. Cheriti, "A real time fuzzy logic power management strategy for a fuel cell vehicle", Energy Conversion and Management, Vol. 80, pp. 63-70, 2014.

[11] A. Ozdemir, I. Yazici, and Z. Erdem, "Modelreference sliding mode control of a three-phase four-leg voltage source inverter for stand-alone distributed generation systems", Turkish J. Electr. Eng. Comput. Sci., Vol. 23, No. 6, pp. 1817-1833, 2015.

[12] I. Vechiu, O. Curea, and H. Camblong, "Transient operation of a four-leg inverter for autonomous applications with unbalanced load", IEEE Trans. Power Electron., Vol. 25, No. 2, pp. 399-407, 2010.

[13] K. Khettab, Y. Bensafia, and S. Ladaci, "Chattering Elimination in Fuzzy Sliding Mode Control of Fractional Chaotic Systems Using a Fractional Adaptive Proportional Integral 
Controller", International Journal of Intelligent Engineering and Systems, Vol. 10, No. 5, pp. 255-266, 2017.

[14] O. Belounis and H. Labar, "Fuzzy Sliding Mode Controller of DFIG for Wind Energy Conversion", International Journal of Intelligent Engineering and Systems, Vol. 10, No. 2, pp. 163-172, 2017.

[15] L. Keltoum, B. Leila, and B. Abderrahmen, "Speed Control of a Doubly-Fed Induction Motor (DFIM) Based on Fuzzy Sliding Mode Controller", International Journal of Intelligent Engineering and Systems, Vol. 10, No. 3, pp. 20-29, 2017.

[16] B. Bendjaima, D. Saigaa, and D.E. Khodja, "Fault Tolerant Control Based on Adaptive Fuzzy Sliding Mode Controller for InductionMotors", International Journal of Intelligent Engineering and Systems, Vol. 10, No. 3, pp. 39-48, 2017.

[17] C, Wang, M.H. Nehrir, and S.R. Shaw, "Dynamic Models and Model Validation for PEM Fuel Cells Using Electrical Circuits", IEEE Transactions on Energy Conversion, Vol. 20, No. 2, pp. 442-451, 2005.

[18] R.F. Mann, J.C. Amphlett, M.A.I. Hooper, H.M. Jensen, B.A. Peppley, and P.R. Roberge, "Development and application of a generalised steady-state electrochemical model for a PEM fuel cell", J. Power Sources, Vol. 86, No.1-2, pp. 173-180. 2000.

[19] F. Z. F. Zhang and Y.Y.Y. Yan, "Selective Harmonic Elimination PWM Control Scheme on a Three-Phase Four-Leg Voltage Source Inverter", IEEE Trans. Power Electron., Vol. 24, No. 7, pp. 1682-1689, 2009.

[20] M. Zhang, D. J. Atkinson, B. Ji, M. Armstrong, and M. Ma, "A near-state three-dimensional space vector modulation for a three-phase fourleg voltage source inverter", IEEE Trans. Power Electron., Vol. 29, No. 11, pp. 57155726, 2014.

[21] Z. Liu, J. Liu, and J. Li, "Modeling, analysis, and mitigation of load neutral point voltage for three-phase four-leg inverter", IEEE Trans. Ind. Electron., Vol. 60, No. 5, pp. 2010-2021, 2013. 